\title{
CORRESPONDENCE
}

\section{INCOMPLETE SEX LINKAGE AND DYSTROPHIES OF THE MACULA}

To the Editors of THE BRITISH JOURNAL OF OPHTHALMOLOGY.

DEAR SIRS,-The paper by Mr. Arnold Sorsby and the genetic note by Dr. Hans Grüneberg on Dystrophies of the Macula which appear in your current number are of the greatest interest. The account of the M. Family suggests to me the presence of incomplete sex linkage. Incompletely sex linked factors are transmitted by a heterozygous parent to those children who are of the same sex as the affected grandparent. If we accept the chart on its face value this has occurred thirteen times out of a possible fourteen. Thus the doubtfully affected great-grandmother has ten affected female grand-children, assuming irregular manifestation in the deaf female in generation III. Her three sons in turn have four affected grandchildren, three boys and a girl. Detailed study of the M. family may not confirm this suggestion, although as stated in the genetic note, incomplete sex linkage has been observed in retinitis pigmentosa. This peculiar mode of inheritance is not widely known amongst ophthalmologists.

Yours faithfully,

W. J. B. RIDDELL.

GLASGOW,

October 10, 1940.

\section{RIBOFLAVIN}

To the Editors of THE BRITISH JOURNAL OF OPHTHALMOLOGY.

DEAR SIRS,-I am offering this brief note about riboflavin now, for two reasons-it has seemed to me to be of considerable value in certain cases, and present circumstances prevent me from making further trials. I hope that other ophthalmic surgeons will experiment with the product and test its usefulness further. Riboflavin is a derivative from vitamin $B$. It has no effect in the cure of pellagra but the want of it is attended with certain symptoms among which photophobia and superficial vascularisation of the cornea are marked. Several papers in American journals have drawn attention to this, and in one the authors stated that they had 
noted improvement in interstitial keratitis. It seemed, therefore, possible that other forms of corneal vascularisation might be helped, I therefore determined to try it when occasion offered.

Riboflavin is put up in tablet form of half milligram by Crookes, its cost is considerable, about 20/- a hundred, and the dose is two to four milligrams a day.

The first case in which I tried it was one of trophic change in the cornea following cerebral thrombosis. The left cornea was the seat of a large ulcer, with vascularity and considerable discomfort. Though the ulcer healed under ordinary treatment, the vascularity and discomfort remained, the addition of four tablets a day of riboflavin at once made the patient comfortable. This was a private patient.

The other cases were seen at the Royal Westminster Ophthalmic Hospital under Messrs. Viner and Moffatt, to whom I offer my thanks.

The second case was one in which a disfiguring leucoma had been tattooed with a central "pupil" to lessen the deformity. The patient for some months had complained of so much discomfort that she wished the tattooing had not been done. There was slight vascularity of the cornea. Riboflavin was ordered, and was followed in two or three days by relief of discomfort.

The third case was a man with intense vascularity of both corneae and photophobia. He was an inpatient. He was certainly improved after giving riboflavin. The photophobia almost entirely left him and the vascularity diminished.

The last case was that of a young man who had been discharged from the Army for " chronic conjunctivitis." There was little to show; there was no evidence of trachoma, little discharge, but there were enlarged vessels, especially below the cornea, and discomfort. I told him that the treatment suggested would very probably not help him, that it was expensive and that therefore I would order him only enough to try from that day (a Friday) till the following Tuesday. He came back on the Tuesday to say that since the Sunday he had complete relief.

I had hoped to investigate similar conditions further, especially herpes frontalis with corneal involvement; but the fact that my house was wrecked by enemy action and that I had to leave London, made further notes impossible. This must be my excuse for this brief and imperfect note.

Yours. faithfully,

HaRold GRIMSDAle. 